\title{
Review on Distributed Energy Storage Systems for Utility Applications
}

\author{
Liuchen Chang, Wenping Zhang, Shuang $\mathrm{Xu}$, and Katelin Spence
}

\begin{abstract}
Energy storage systems (ESSs) can improve the grid's power quality, flexibility and reliability by providing grid support functions. This paper presents a review of distributed ESSs for utility applications. First, a review of the energy storage market and technology is presented, where different energy storage systems are detailed and assessed. Then, ESS grid support functions are presented and seven types of functions are described. Finally, the power electronic converters for distributed ESSs are reviewed and the corresponding features and performances are evaluated. The main objective of this paper is to provide an updated reference regarding ESSs for utility applications to researchers and practitioners in the field of power electronics.
\end{abstract}

Index Terms-Energy storage systems, grid support functions, power conversions.

\section{INTRODUCTION}

$\mathrm{C}$ LIMATE change and global warming pose a threat to our environment and health and are growing in significance due to the increase of greenhouse gas emissions [1][2]. Renewable energy resources (e.g. wind and photovoltaic etc.) are gaining attention due to their low emissions and abundance. However, the intermittent nature of renewable resources like wind and solar energy also brings new issues regarding the grid's reliability, flexibility and power quality. Therefore, energy storage systems (ESSs) are being introduced to address these issues. Smart grid technologies make it possible to reduce and shift loads and support renewables [3]-[4]. The ESSs in a smart grid are able to improve grid reliability, flexibility and power quality by providing grid support functions such as ancillary services and peak load reduction [5].

Based on energy storage technologies, ESSs can be divided into five categories: electrochemical, electromagnetic, mechanical, chemical, and thermal [1]-[4]. Each storage system has distinctive characteristics in terms of power rating, discharge time, power and energy density, response time, self-discharge losses, life and cycle time, etc. , [6]-[9]. These features should be taken into account to determine their suitability for different grid support functions, such as peak shaving, energy arbitrage, integration of renewables, voltage

Manuscript received November 23, 2017.

The authors are with the Emera \& NB Power Research Centre for Smart Grid Technologies, Dept. of Electrical and Computer Engineering, University of New Brunswick, Fredericton, NB E3B5A3, Canada (e-mail: lchang@unb.ca; wzhang18@unb.ca; Shuang.Xu@unb.ca; Katelin.Spence@ unb.ca).

Digital Object Identifier 10.24295/CPSSTPEA.2017.00025

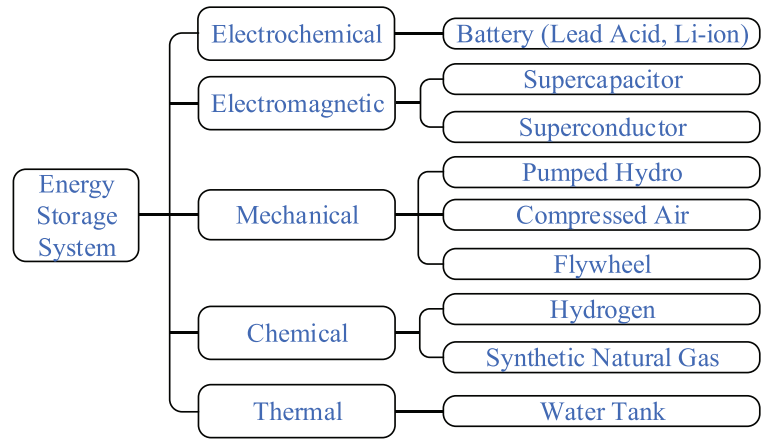

Fig. 1. ESS classifications.

and frequency regulation, harmonics compensation, spinning and non-spinning reserves, and black start [15]-[20]. In order to fulfill these functions, power electronic conversion technologies are critical in controlling the power flow between the grid and ESSs. Two power conversion structures, common DC bus and $\mathrm{AC}$ bus, are normally applied. In addition, various bidirectional converters (DC/DC, DC/AC, and AC/ $\mathrm{AC})$ are employed to improve the system performance. System performance can pertain to efficiency, reliability, output distortion and power density.

The objective of this paper is to review ESS technologies, grid support functions and power converters for ESSs. In this paper, Section II presents a review of the energy storage market and technology, where different energy storage systems are detailed and assessed. Section III presents the ESS grid support functions and seven types of functions are described. In Section IV, the power electronic converters for ESSs are reviewed and the corresponding features and performances are evaluated. Section V concludes this paper by remarking on future trends in these areas.

\section{Energy Storage Technology}

The five categories of ESSs are presented in Fig. 1 [1].

The market of ESSs for utility applications has been developing rapidly as presented in Fig. 2, where the market is still dominated by pumped hydro storage (PHS) systems [2]. With the technological development, new forms of ESSs, such as electrochemical ESSs, have grown significantly.

\section{A. Energy Storage Technologies}

\section{1) Electrochemical ESS}

Electrochemical ESSs are generally referred to as batteries. A traditional battery is lead acid (LA). LA batteries have 


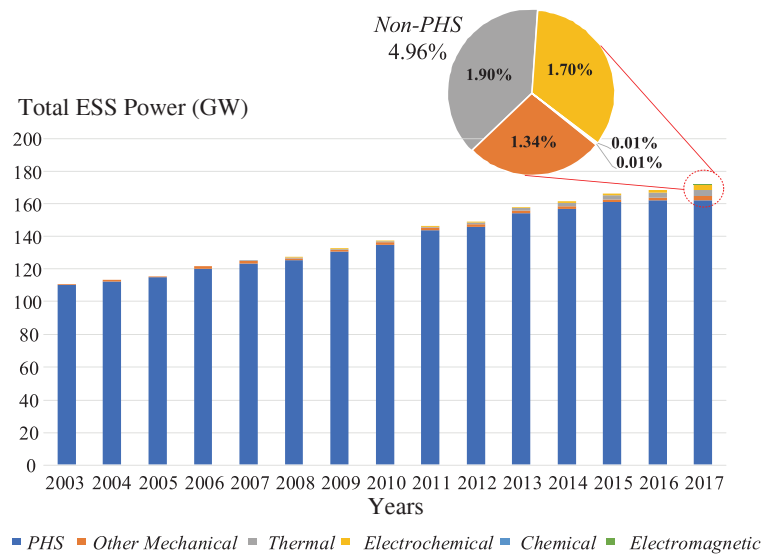

Fig. 2. Global power capacity of ESS.

been widely applied due to their well-developed technology and low costs. However, the disadvantages, such as limited cycle lifetime, low energy density and environmental impact, will limit their application in the future [3].

On the contrary, lithium ion (Li-ion) batteries have higher power and energy density, higher number of lifetime cycles, and higher efficiency, which are promising for grid applications [1]. However, the safety risk is still a challenge because of their flammable electrolytes. Additionally, the Li-ion battery costs are relatively high.

Recently, some research has focused on flow batteries, such as vanadium redox batteries (VRBs). VRBs feature extremely long lifespan and lifetime cycles with power up to several MW [4]. However, the main drawback is that the efficiency of VRBs drops significantly in cold temperatures, which narrows its application.

\section{2) Electromagnetic ESS}

Electromagnetic ESSs can store energy in either electric fields (e.g. supercapacitors) or magnetic fields (e.g. superconductors). Compared with batteries, supercapacitors have higher reliability, lower maintenance, and lower environmental impact [5]. However, low energy density makes supercapacitors unsuitable for long-term discharging applications.

Superconducting magnetic energy storage (SMES) features fast dynamic responses. Theoretically, the energy in SMES can be stored forever due to zero losses of superconducting materials [6]. However, there is a strict requirement of maintaining a low temperature for the SMES to operate and the corresponding costs limit its applications.

\section{3) Mechanical ESS}

Mechanical ESSs transform energy between mechanical and electrical forms. Surplus electricity is taken from the grid during off-peak hours and stored mechanically (by gravitational potential or rotational energy) until it is needed; it is then released back to the grid [7].

The most common system is pumped hydro, which has a high power and energy rating, long lifespan, and practically unlimited life cycles. However, the dynamic response is slower than some other ESSs. PHS also has a large geographical footprint and specific topographical requirements.

Compressed air energy storage (CAES) systems store energy in the form of intermolecular potential energy. It features a large capacity and medium geographical dependency. However, the round-trip efficiency is low because of heat dissipation [8].

Compared with other mechanical ESSs, flywheel energy storage (FES) systems have the highest power density and lowest geographical dependency. However, the primary disadvantage is that the friction between rotor and shaft affects the system efficiency, in addition to the high costs.

\section{4) Chemical ESS}

Typical chemical ESSs are hydrogen ESS and synthetic natural gas (SNG) ESS. A hydrogen ESS decomposes water $\left(\mathrm{H}_{2} \mathrm{O}\right)$ into hydrogen $\left(\mathrm{H}_{2}\right)$ and oxygen $\left(\mathrm{O}_{2}\right)$ with electricity. Then, $\mathrm{H}_{2}$ can be stored in high-pressure tanks and fed into a fuel cell to produce electricity. This is an effective way of storing a large amount of energy for a long period, which can be applied for long term or even seasonal applications [9]. However, the main limitations are the high costs for obtaining hydrogen and full cell equipment and the safety risk of storing pressurized $\mathrm{H}_{2}$.

Another method of long term electricity storage uses SNG. For the same amount of energy storage, the pressure of a SNG tank is lower due to the higher density of SNG. However, compared with hydrogen ESS, the conversion losses of SNG ESS are higher and the round-trip efficiency is lower [10].

\section{5) Thermal ESS}

Water storage tanks can be adapted for use as thermal ESSs. They work for load shifting functions, where the temperature of a water tank is raised during off-peak hours so that hot water and warm air can be provided during peak hours without drawing as much electricity. However, this scenario is essentially load control and the regulation capability is inflexible, especially during summer months or in hot regions where limited hot water or heat is needed [11].

\section{B. ESS Comparison}

Different ESSs are compared in the following in terms of power density, energy density, power capacity, discharge time, cycling times, and efficiency etc.

\section{1) Power \& Energy Density [1]-[4]}

Fig. 3 presents the power and energy density ranges of different ESSs in terms of power or energy per liter.

Based on Fig. 3, it can be seen that most batteries and flywheels have relatively moderate energy and power densities. Comparatively, Li-ion batteries have higher energy and power densities than LA batteries. Also, the energy density of the VRB flow batteries is low. Mechanical ESSs (PHS and CAES) have low power and energy densities, since large reservoirs are required. Supercapacitors have high power densities but low energy densities and in comparison, SMESs have a lower power density. The energy densities of the hydrogen and SNG ESSs are relatively high. 


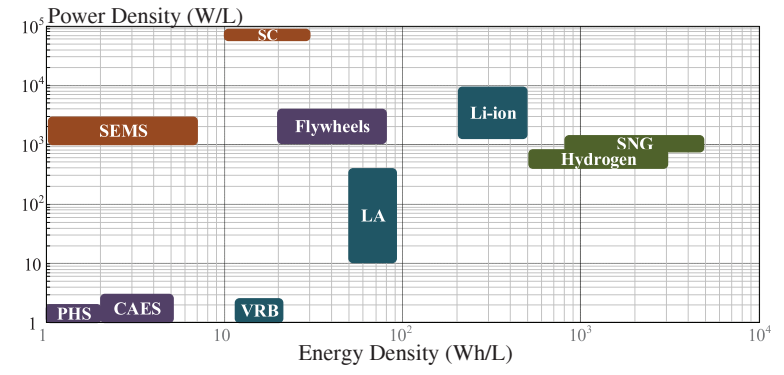

Fig. 3. Power and energy density comparison for ESSs.

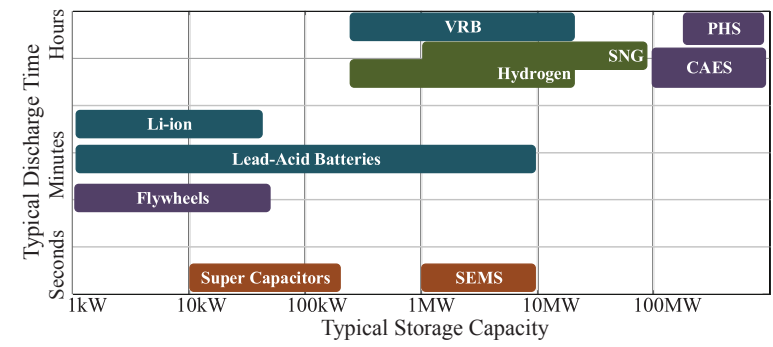

Fig. 4. Typical power capacity and discharge time for ESSs.

\section{2) Power Capacity and Discharge Time [4]-[11]}

Based on Fig. 4, it can be seen that electromagnetic ESSs, such as SC and SMES, have short discharge times of several seconds. This makes them useful for short-term grid support functions. On the contrary, mechanical and chemical ESSs have long discharge times in the range of hours, which can be applied for long-term functions such as load shifting. The PHS and CAES mechanical ESSs are suitable for high-power applications, as are the hydrogen and SNG chemical ESSs. Electrochemical and electromagnetic ESSs generally have a lower power capacity, but their applications in the distributed energy systems secure them a decent market share.

\section{3) Additional Features [5]-[9]}

Additional technical characteristics are presented in TABLE I. It can be seen that batteries, SC and SMES all have fast response times. Mechanical ESSs, including PHS, CAES and flywheels, have higher cycling times. Additionally, PHS, CAES and hydrogen ESSs have very small daily self-discharge ratios, which means the energy can be stored for a long time.

\section{ESS GRID SupPoRT FunCtIONS}

Based on response time, grid support functions can be divided into three categories: second-level, minute-level and hour-level, as presented in Fig. 5 [12]. In order to be useful for grid support functions, ESSs are required to have the both fast power response and high energy capacity.

\section{A. Peak Shaving \& Load Leveling}

As shown in Fig. 6(a), if the load demand $P_{\text {Load }}$ is higher than the maximum scheduled generation $P_{S \text { max }}$, ESSs can discharge power to shave the peak load. If the load demand
TABLE I

Additional Technical Characteristics

\begin{tabular}{l|ccccc}
\hline \hline & $\begin{array}{c}\text { Daily } \\
\text { Self-Disc } \\
(\%)\end{array}$ & $\begin{array}{c}\text { Lifetime } \\
\text { (years) }\end{array}$ & $\begin{array}{c}\text { Cycling } \\
\text { Times } \\
\text { (cycles) }\end{array}$ & $\begin{array}{c}\text { Discharge } \\
\text { Efficiency } \\
(\%)\end{array}$ & $\begin{array}{c}\text { Response } \\
\text { Time }\end{array}$ \\
\hline LA & $0.1-0.3$ & 3 & $\sim 1000$ & $\sim 85$ & milliseconds \\
Li-ion & $0.1-0.3$ & $5-10$ & $\sim 5000$ & $\sim 85$ & milliseconds \\
VRB & Small & $5-15$ & $\sim 10000$ & $\sim 85$ & milliseconds \\
PHS & $\sim 0$ & $40-60$ & $\sim 30000$ & $\sim 87$ & minutes \\
CAES & $\sim 0$ & $20-40$ & $\sim 10000$ & $\sim 75$ & minutes \\
FES & 100 & $\sim 15$ & $\sim 20000$ & $\sim 90$ & seconds \\
SC & $20-40$ & $10-30$ & $\sim 50000$ & $\sim 95$ & milliseconds \\
SMES & $10-15$ & $20+$ & $\sim 100000$ & $\sim 95$ & milliseconds \\
$\mathrm{H}_{2}$ & $\sim 0$ & 15 & $\sim 10000$ & $\sim 59$ & seconds \\
SNG & $\sim 0$ & 15 & $\sim 20000$ & $\sim 50$ & seconds \\
\hline \hline
\end{tabular}

\begin{tabular}{|c|c|c|}
\hline $\begin{array}{c}\text { Fast } \\
\text { (Seconds) }\end{array}$ & $\begin{array}{r}\text { Medium } \\
\text { (Minutes) }\end{array}$ & $\begin{array}{c}\text { Slow } \\
\text { (Hours) }\end{array}$ \\
\hline $\begin{array}{l}-\quad \text { Voltage Regulation } \\
\text { Automatic Generation } \\
\text { Control (AGC) } \\
\text { Harmonics Suppression }\end{array}$ & $\begin{array}{l}\bullet \text { Reserve } \\
\bullet \text { Black Start } \\
\bullet \text { Load Following } \\
- \text { Frequency Regulation }\end{array}$ & $\begin{array}{l}\text { - Load Levelling \& Peak- } \\
\text { Shaving } \\
\bullet \quad \text { Energy Arbitrage }\end{array}$ \\
\hline $\begin{array}{c}\text { SMES } \\
\text { Batteries } \\
\text { Flywheels }\end{array}$ & $\begin{array}{r}H i g h \boldsymbol{E}_{\boldsymbol{r}} \\
\text { Decouple Gen }\end{array}$ & $\begin{array}{c}\text { PHS } \\
\text { CAES } \\
\text { Hydrogen } \\
\text { SNG }\end{array}$ \\
\hline
\end{tabular}

Fig. 5. Grid support function diagram.

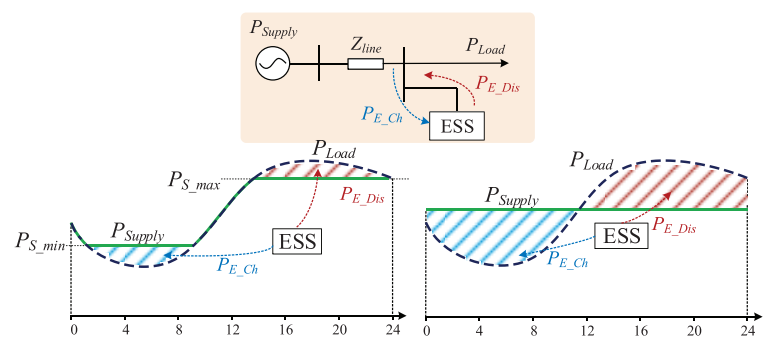

(a) Peak Shaving

(b) Load Leveling

Fig. 6. Peak shaving \& load leveling function.

$P_{\text {Load }}$ is lower than the minimum scheduled generation $P_{S_{-m i n}}$, ESSs can store the excess energy. Load leveling is similar to peak shaving, as shown in Fig. 6(b). The difference is that peak shaving is focused on flatting the load peak, while load leveling attempts to flatten the entire load [13]. These functions can reduce fuel consumptions and carbon dioxide $\left(\mathrm{CO}_{2}\right)$ emissions, decrease maintenance costs, and increase system reliability. Research related to this focuses on four aspects:

1) Obtaining the optimum charging \& discharging schedule for ESSs;

2) Finding the optimum size and placement for ESSs;

3) Assessing economic costs for customers and utilities and improving the economic feasibility;

4) Implementing distributed ESSs instead of large-scale ESSs.

Recently, research has also focused on the use of electric vehicles (EVs) for peak-shaving. However, the main challenges are the availability of EVs, aggregated control of largescale EVs, and the corresponding infrastructure for EV inte- 


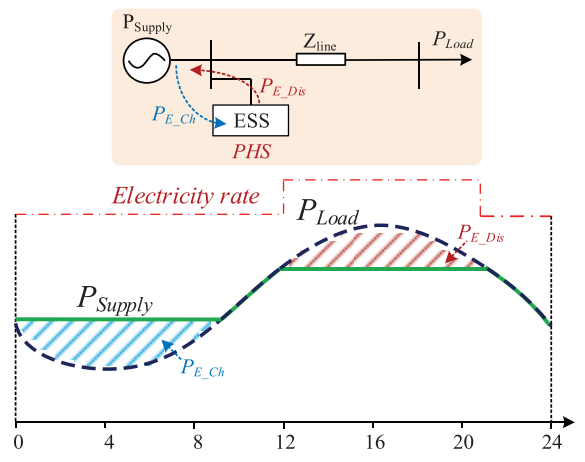

Fig. 7. Energy arbitrage function.

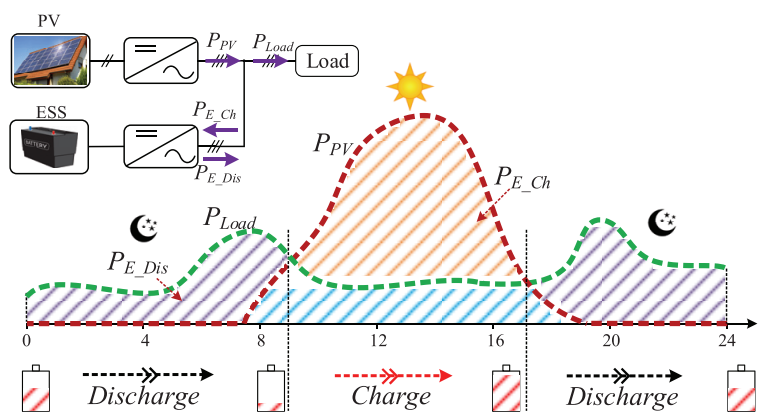

Fig. 8. Integration of PV systems.

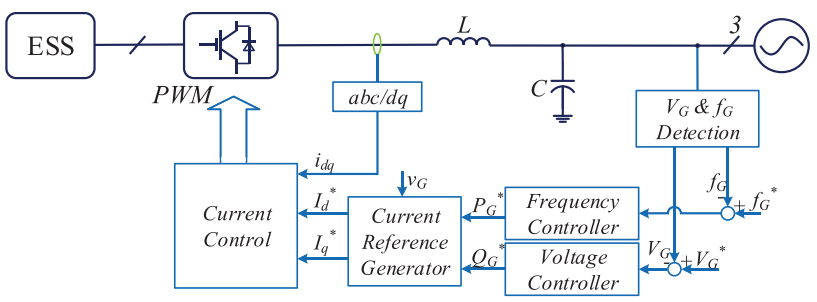

Fig. 9. Voltage \& frequency regulation control diagram.

gration with the grid.

\section{B. Energy Arbitrage}

Energy arbitrage is attempting to earn a profit by charging the ESS at a lower electricity rate and selling the stored energy at a higher price, which is presented in Fig. 7 [13]. Traditionally, this function is implemented by pumped hydro storage (PHS) systems. With the wide application of EVs, numerous charging scheduling are proposed for energy arbitrage. The large quantity of EVs in the near future could contribute to a new concept of the energy market.

Energy arbitrage research is similar to peak-shaving functions; which includes the optimum ESS scheduling for maximizing the profits, ESS sizing, economic assessment, and implementation of distributed ESSs, especially EVs.

\section{Integration of Renewables}

The intermittent nature of renewable energy sources introduces new challenges for power system operation. The main

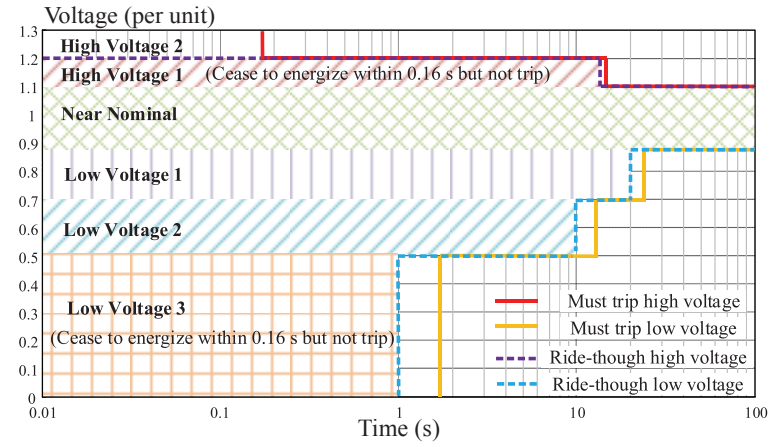

Fig. 10. Voltage ride-through requirements.

issue is the unpredictable power imbalance between generation and demand [14]-[15]. Therefore, ESSs are introduced to balance the intermittency. In addition, ESSs can be used to smooth out fast load fluctuations, regulate frequency, etc. Integration of renewables requires more system resources to provide ancillary services (seconds and minute-levels) and energy dispatch (hour-level). While this topic covers a wide scope, only longer term energy storage is described here. Fig. 8 presents the basic concept of ESSs supporting PV integration for load balancing. The ESSs are charged in the daytime, when PVs generate power, and are discharged at night when PV power is unavailable. As a result, the system power is balanced and the reliability is enhanced. There are four research topics related to this:

1) Finding optimum system integration configurations;

2) Mathematically modelling intermittency for renewable energy sources;

3) Selecting ESS type, size, and siting to optimize cost;

4) Designing control structure and scheduling strategies for energy flow management.

\section{Voltage \& Frequency Regulation}

ESSs can be used to absorb real power when the grid frequency is higher than nominal and inject real power when the grid frequency drops below nominal [16]-[17]. By doing this, they help to stabilize the grid's frequency. Similarly, ESS can contribute to voltage regulation by injecting or absorbing reactive power. The control diagram is presented in Fig. 9. SCs, FESs, and batteries are normally adopted for frequency and voltage regulation because of their fast response.

UL 1741 specifies the voltage and frequency ride-through requirements for distributed energy resources (DERs), which are shown in Fig. 10 and Fig. 11.

\section{E. Harmonic Compensation}

Due to the increasing presence of nonlinear loads and power electronic converters, the grid power quality is deteriorated significantly. To compensate grid harmonics, numerous active and passive filtering techniques were developed [18]-[19]. However, installing additional filters is not favorable due to extra costs. An alternative is utilizing ESSs to compensate harmonics where harmonic compensation can 


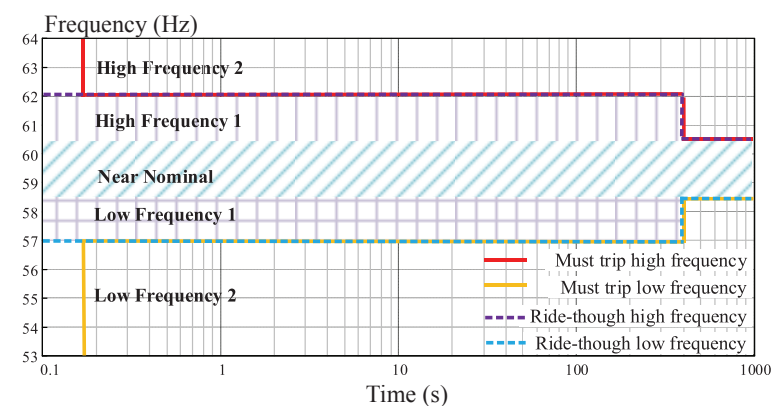

Fig. 11. Frequency-ride through requirements.

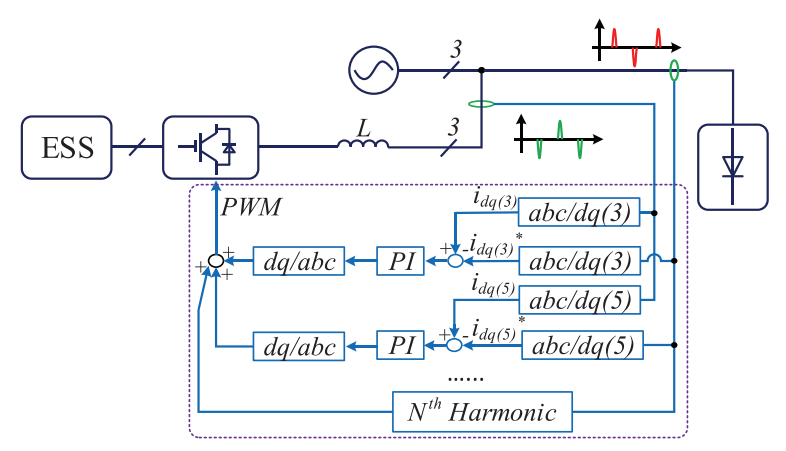

Fig. 12. Harmonics compensation control diagram.

TABLE II

MaXimum Harmonic CurRent Distortion

\begin{tabular}{ccccccc}
\hline \hline $\begin{array}{c}\text { Harmonic } \\
\text { Order } h\end{array}$ & $h<11$ & $11 \leq h<17$ & $17 \leq h<23$ & $23 \leq h<35$ & $h \geq 35$ & $\begin{array}{c}\text { Total } \\
\text { Demand } \\
\text { Distortion }\end{array}$ \\
\hline $\begin{array}{c}\text { Percent } \\
(\%)\end{array}$ & 4.0 & 2.0 & 1.5 & 0.6 & 0.3 & 5.0 \\
\hline \hline
\end{tabular}

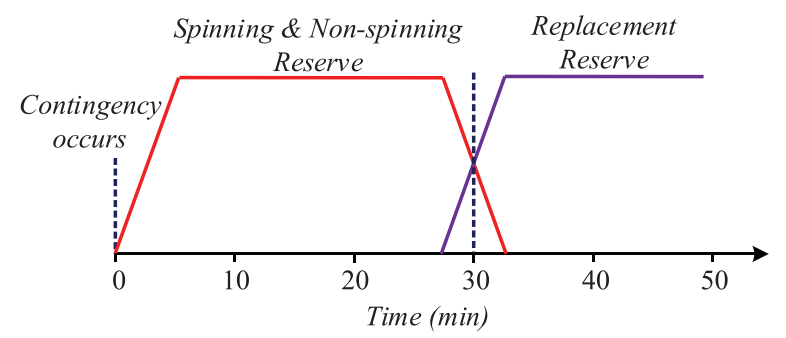

Fig. 13. Different reserves respond to a contingency.

be integrated with primary grid support functions. Fig. 12 presents a harmonic compensation control diagram, where the $3^{\text {rd }}$ and $5^{\text {th }}$ harmonics are transformed into corresponding $d-q$ coordinates for current harmonic suppression.

IEEE 1547 specifies the maximum harmonic current distortion for DERs, as shown in TABLE II.

\section{F. Reserves}

When a contingency occurs and is large enough to affect the power system frequency, the spinning reserves instantly respond as shown in Fig. 13 [20]. Then, the spinning and

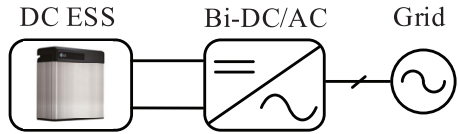

(a) Single-Stage Structure

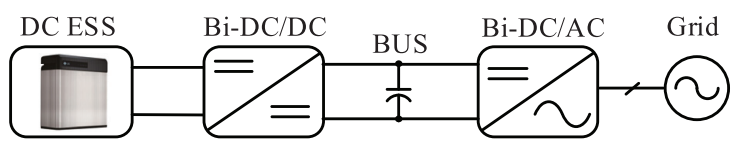

(b) Two-Stage Structure

Fig. 14. DC ESS structure.

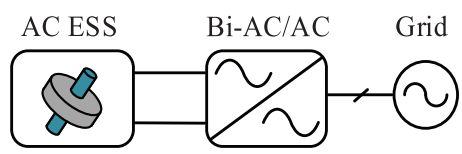

(a) Single-Stage Structure

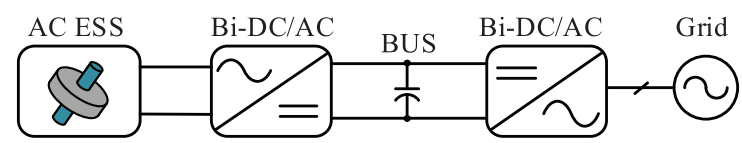

(b) Two-Stage Structure

Fig. 15. AC ESS structure.

non-spinning reserves are normally relieved by replacement reserves within 30 minutes. Therefore, the reserves are an important resource that can safeguard power systems without involuntary load shedding. Currently, battery storage systems are being gradually applied for spinning reserve to replace conventional generators which are slow for grid synchronization due to startup issues.

Increasing the grid reserve size can increase the system reliability, but with higher costs. Numerous approaches have been proposed to determine the optimum spinning reserve size as a compromise between reliability and costs. Currently, with the increasing penetration of EVs, some research is also conducted on evaluating the spinning reserve ability of EVs.

\section{G. Black Start and Load Following}

ESSs can provide black start capability, which helps a system startup from a shutdown. An example is the Huntorf CAES plant that provides black-start power to nuclear units located near to the North Sea [5], [21].

Also, ESSs can provide support for following the load demand changes. Some relevant research and demonstration projects can be found in [5] and [22].

\section{ESS Power Converter Technology}

Typical distributed ESSs are batteries, supercapacitors, SMESs and flywheels. These ESSs can be categorized as DC ESSs (e.g. batteries) and AC ESSs (e.g. flywheels). Fig. 14 and Fig. 15 present the typical structures for DC ESSs and AC ESSs respectively; including single-stage and two-stage structures.

From Fig. 14 and Fig. 15, typical power converters for 


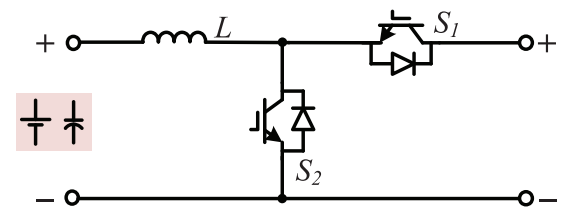

(a) Single Buck/Boost

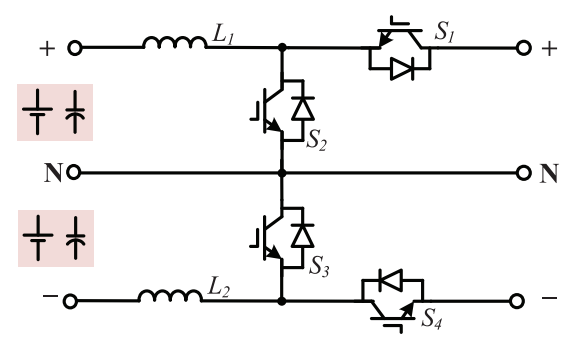

(b) Series-Output Dual Buck/Boost

Fig. 16. Bidirectional buck/boost converter.

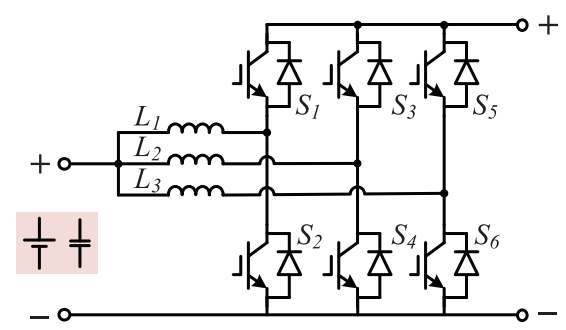

Fig. 17. Bidirectional interleaved DC-DC converter.

ESSs include bidirectional DC/DC, bidirectional DC/AC, and bidirectional $\mathrm{AC} / \mathrm{AC}$. In general, power converters should have the following features:

1) Bidirectional power flow;

2) High efficiency.

In addition to these features, for different applications:

3) Fast response (e.g. frequency regulation applications);

4) High peak power (e.g. peak shaving applications).

\section{A. Bidirectional DC/DC Converters (Bi-DC/DC)}

A typical non-isolated Bi-DC/DC structure is the buck/ boost converter, which is presented in Fig. 16 [23]-[24]. Compared to Fig. 16(a), the topology in Fig. 16(b) can be used for the applications where access to the DC bus neutral-point is needed. The buck-boost converter has a low number of power electronic devices, which leads to lower costs and higher reliability than other converters. However, it cannot be used in applications where isolation is required. Its voltage step-up ratio is relatively low, making it unsuitable for low-voltage ESSs. Additionally, the input current ripple is relatively high, which may be harmful for some energy storage, such as batteries.

In order to suppress the current ripple of buck/boost converters, interleaved topologies are widely applied. Fig. 17 presents the interleaved buck/boost converter. In addition to suppressing the ripple, a higher power rating can be achieved with the interleaved technology. However, the number of

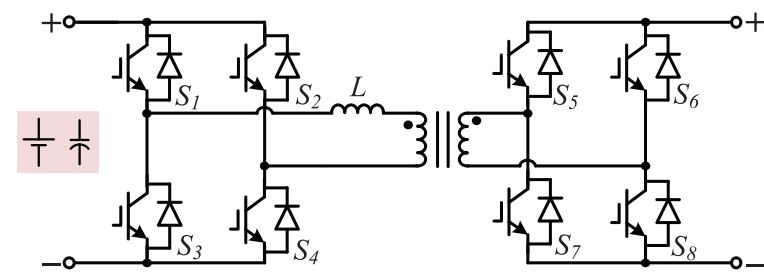

Fig. 18. Bidirectional dual active bridge DC-DC converter.

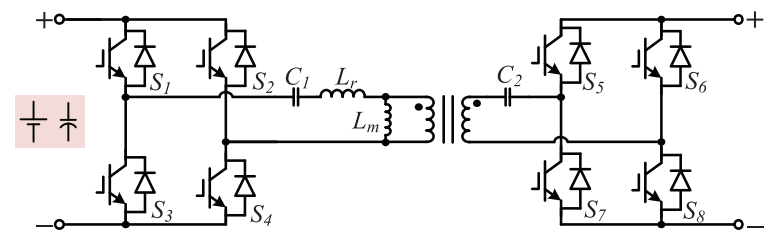

Fig. 19. CLLC DC/DC converter.

switches is increased which results in higher costs.

When isolation is required, dual active bridge (DAB) DC/ DC converters are commonly selected as shown in Fig. 18. The output power can be easily regulated and zero voltage switching (ZVS) can be achieved [25]-[26]. However, compared with the non-isolated converter in Fig. 16, there are more power electronic devices, which reduces the system reliability. Furthermore, the conduction losses and turn-off loss are higher.

To improve the efficiency of DAB converters, numerous modifications, such as $L C, L C L$, and $C L L C$ converters, are proposed [27]-[28]. Fig. 19 presents the $C L L C$ DC/DC converter. The proposed topologies have higher efficiency but are more complex. Also, the output power regulation capability is limited due to soft switching.

\section{B. Bidirectional DC/AC Converters (Bi-DC/AC)}

Currently, the most widely used DC-AC converters are two-level inverters as shown in Fig. 20, which can be single-phase and three-phase [29]. The bidirectional two-level DC-AC inverter has a compact design and high reliability. However, the switches experience higher voltage stress and the system efficiency is relatively low. Also, the output distortion is higher than multilevel inverters.

Multilevel DC/AC converters, such as the neutral point clamped (NPC) shown in Fig. 21(a), are introduced to improve the system efficiency [30]. Recently, the T-type topology, as shown in Fig. 21(b), has been widely used due to its higher efficiency and higher reliability. However, the neutral point voltage balance is still a key issue for three-level converters.

Operating with DC currents, SMESs require current source inverters (CSIs) [31], shown in Fig. 22. The dead time for the device gate controls is not required for CSIs. It is worth mentioning that the coils in SMESs are not allowed to be open, thus a bypass switch is normally paralleled with the coil during the standby mode. In addition, a leakage current occurs in CSIs due to the common mode voltage. Therefore, 


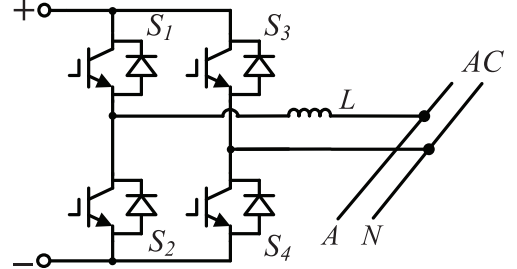

(a) Single-Phase

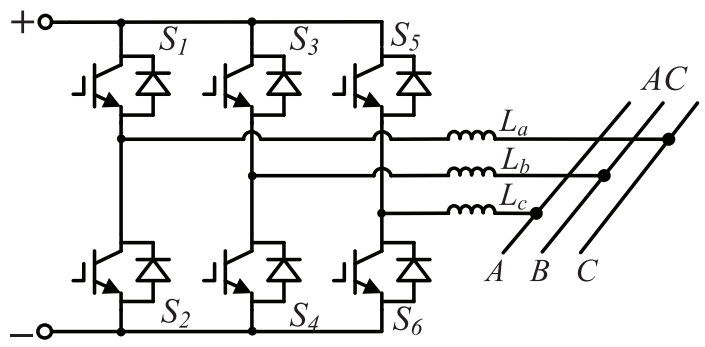

(b) Three-Phase

Fig. 20. Bidirectional two-level DC-AC converter.

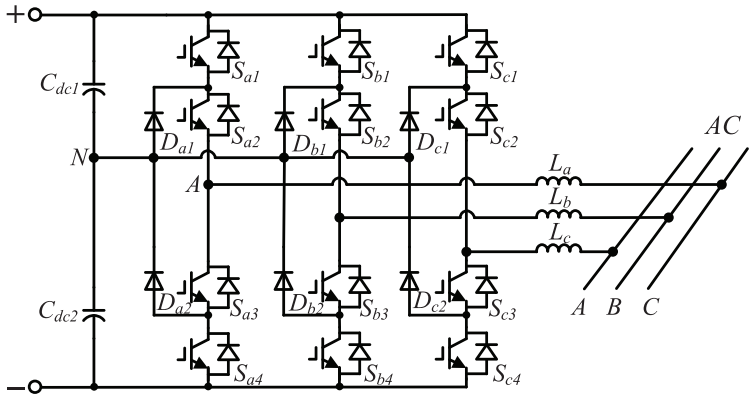

(a) Neutral Point Clamped

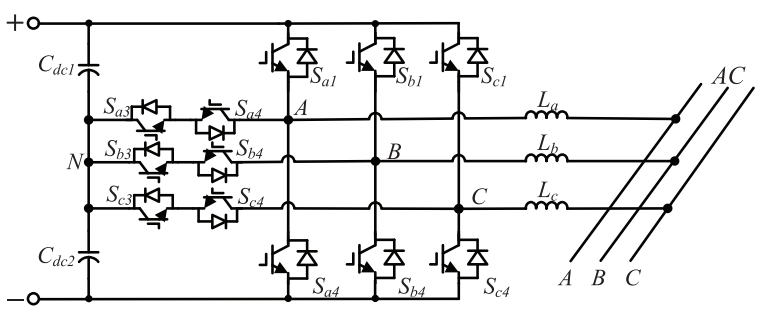

(b) T-Type

Fig. 21. Neutral point clamped multilevel DC-AC converter.

more topology modifications and modulation techniques have been developed to improve the performance of CSIs.

\section{Bidirectional AC/AC Converters (Bi-AC/AC)}

A typical $\mathrm{AC}-\mathrm{AC}$ converter is the matrix converter, which is presented in Fig. 23. The matrix converter eliminates the DC-link, which has its merits. However, more bi-directional switches are involved, which makes the system more complex and costly [32].

ESSs are commonly combined to achieve a high power rating, large scale or high reliability for utility applications. Furthermore, parallel DC and AC busses are adopted for

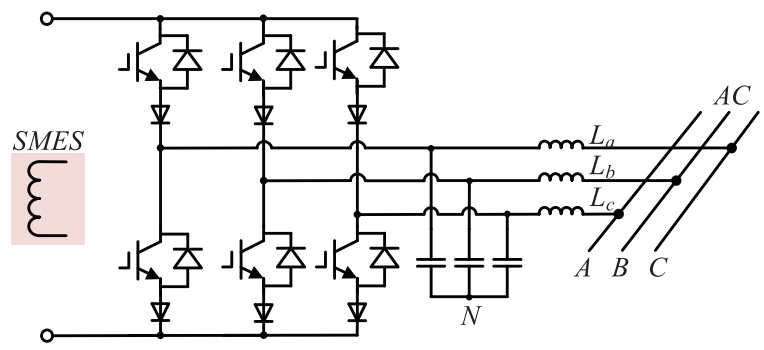

Fig. 22. Three-phase current source inverter.

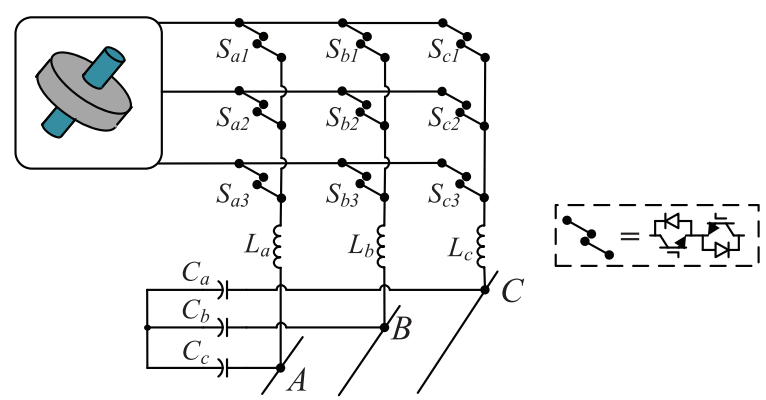

Fig. 23. Matrix AC-AC converter.

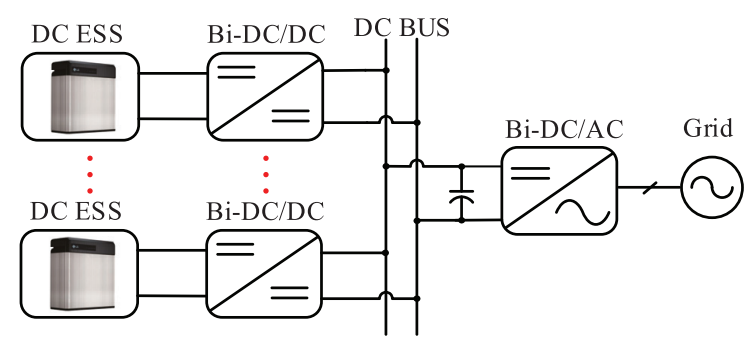

(a) Parallel DC Bus

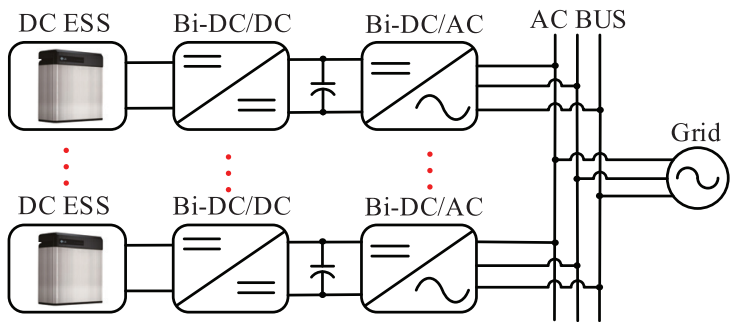

(b) Parallel AC Bus

Fig. 24. Parallel DC and AC bus structures.

multi-ESSs applications, which is shown in Fig. 24. It is worth mentioning that for the parallel DC bus structure in Fig. 24(a), the reliability of DC/AC converter is critical; since all energy storage modules feed into one inverter.

Additionally, series DC or AC bus configurations are widely adopted for large-scale ESS applications. Fig. 25 presents a series DC bus structure [33], where high DC bus voltage and galvanic isolation can be achieved. This topology is suitable for DC inputs with low voltages or large variations. However, there is a decrease in efficiency when large voltage variations happen.

Modular multilevel cascaded (MMC) converters are one of 


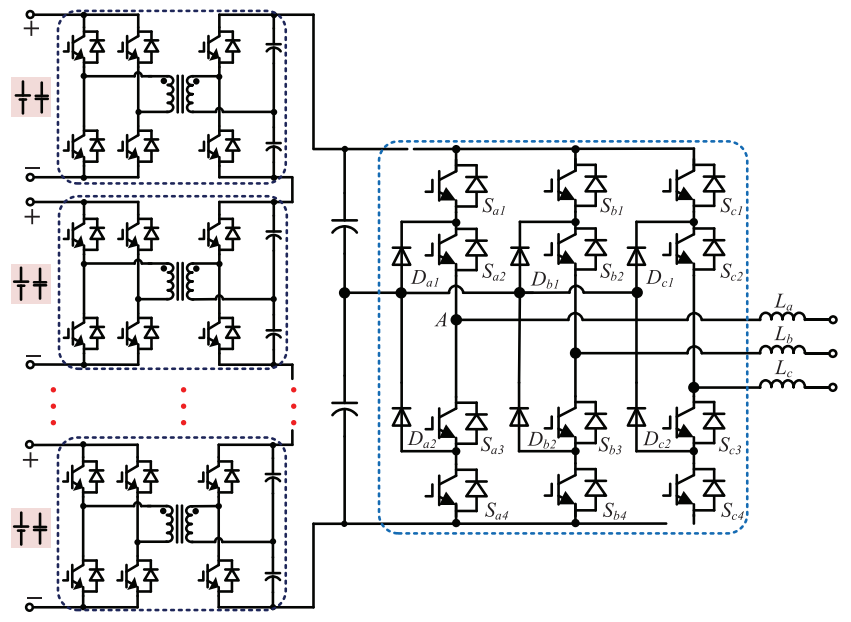

Fig. 25. Series DC bus configuration.

the typical series AC bus structures, shown in Fig. 26(a). This topology features higher efficiency, lower output harmonics, and higher fault-tolerance; which is applied for large-scale battery ESSs [34]. Each bridge cell can dependently control the state of charge (SOC) of a battery. However, the additional hardware and software for balancing among different modules is still a main drawback. Instead of using H-bridge converters, the bridge cells can adopt other topologies for different applications. Fig. 26(b) presents two types of cell topologies.

\section{Conclusions}

This paper gives an overview of recent developments in ESS technologies. While there are various ESSs in the utility market, the continued development of low-cost and high-performance solutions is the main direction. Newly emerging ESS technologies need intensive investigation to gain utility acceptance in future. The factor of environmental friendliness will play a more and more important role for the fates of different ESSs.

No single storage type can satisfy all the utility requirements, therefore the selection of energy storage technologies is a key issue. Adopting hybrid ESSs, which can achieve multi-facet objectives, is a growing trend.

It is critical to optimize the design of ESSs in utility application by determining the size (e.g. power and energy capacity) and site of the ESSs. Various optimization methodologies, which consider costs, reliability and post-compensation performance indicators, have been proposed for ESS applications and will continue to be developed. Current power dispatch and scheduling for most ESSs are for ideal conditions. In the future various uncertainty factors, including renewable forecast error, technical constraints, and market rules, should be taken into account. Seeking a more robust optimization scheduling is at the forefront for research in utility operation.

The objective for power converter developments is to achieve high power, high efficiency, high reliability, and high power

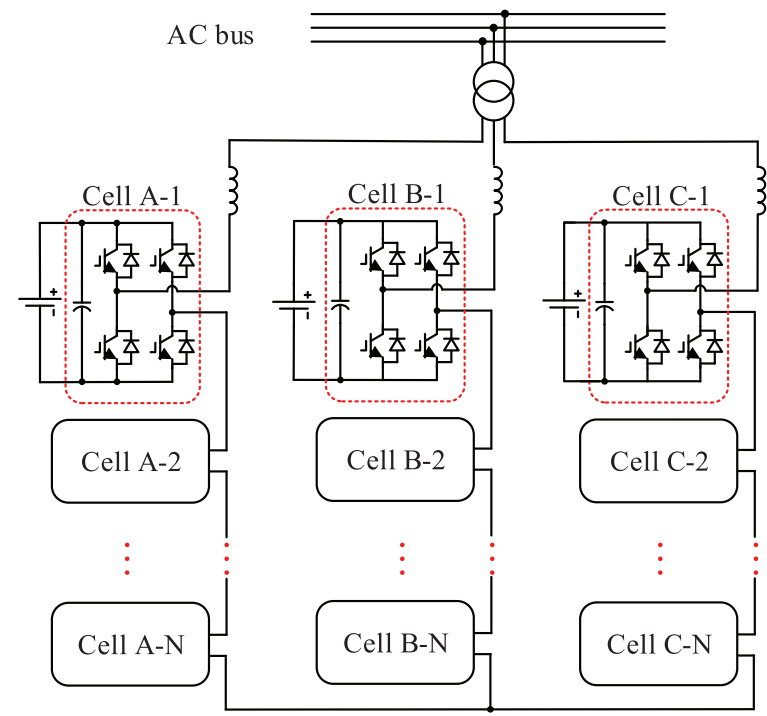

(a) Cascaded H-Bridge Converters

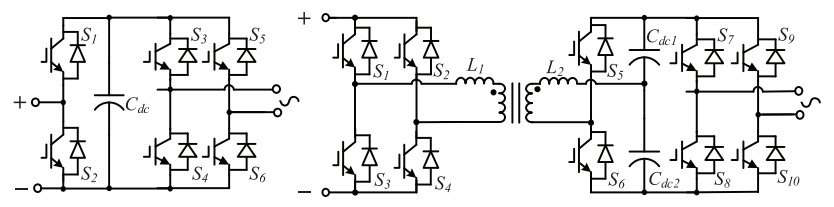

(b) Different Cell Topologies

Fig. 26. Series AC bus configuration.

quality. For DC/AC converters, multilevel topologies are still dominant in the market high power units with higher efficiency and lower harmonic distortion; and two-level topologies are mainly for low power units. With increasing renewable energy penetration, the reliability of power electronic converters has become critically important.

\section{REFERENCES}

[1] H. Chen, T. Cong, W. Yang, C. Tan, Y. Li, and Y. Ding, "Progress in electrical energy storage system: A critical review," Progress in Natural Science, vol. 19, no. 3, pp. 291-312, 2009.

[2] O. M. Toledo, D. O. Filho, and A. S. Diniz, "Distributed photovoltaic generation and energy storage systems: A review," Renewable and Sustainable Energy Reviews, vol. 14, no. 1, pp. 506-511, 2010.

[3] S. Vazquez, S. M. Lukic, E. Galvan, L. G. Franquelo, and J. M. Carrasco, "Energy storage systems for transport and grid applications," IEEE Transactions on Industrial Electronics, vol. 57, no. 12, pp. 3881-3895, 2010.

[4] H. Zhao, Q. Wu, S. Hu, H. Xu, and C. Rasmussen, "Review of energy storage system for wind power integration support," Applied Energy, vol. 137, no. 1, pp. 545-553, 2015.

[5] X. Luo, J. Wang, M. Dooner, and J. Clarke, "Overview of current development in electrical energy storage technologies and the application potential in power system operation," Applied Energy, vol. 137, no. 1, pp. 511-536, 2015.

[6] D. O. Akinyele, and R. K. Rayudu, "Review of energy storage technologies for sustainable power networks," Sustainable Energy Technologies and Assessments, vol. 8, no.12, pp. 74-91, 2014.

[7] E. Barbour, I. G. Wilson, J. Radcliffe, Y. Ding, and Y. Li, "A review of pumped hydro energy storage development in significant international electricity markets," Renewable and Sustainable Energy Reviews, vol. 61, no. 8, pp. 421-432, 2016.

[8] S. Briola, P. D. Marco, R. Gabbrielli, and J. Riccardi, "A novel mathe- 
matical model for the performance assessment of diabatic compressed air energy storage systems including the turbomachinery characteristic curves," Applied Energy, vol. 178, no. 9, pp. 758-772, 2016.

[9] W. Choi et al., "Reviews on grid-connected inverter, utility-scaled battery energy storage system, and vehicle-to-grid applicationchallenges and opportunities," in 2017 IEEE Transportation Electrification Conference and Expo (ITEC), Chicago, IL, 2017, pp. 203-210.

[10] M. Yilmaz and P. T. Krein, "Review of battery charger topologies, charging power levels, and infrastructure for plug-in electric and hybrid vehicles," IEEE Transactions on Power Electronics, vol. 28, no. 5, pp. 2151-2169, 2013.

[11] S. F. Tie and C. W. Tan, "A review of energy sources and energy management system in electric vehicles," Renewable and Sustainable Energy Reviews, vol. 20, no. 4, pp. 82-102, 2013.

[12] J. Aghaei and M. Alizadeh, "Demand response in smart electricity grids equipped with renewable energy sources: A review," Renewable and Sustainable Energy Reviews, vol. 18, no. 2, pp. 64-72, 2013.

[13] M. Uddin, M. F. Romlie, M. F. Abdullah, S. A. Halim, A. H. Bakar, and T. C. Kwang, "A review on peak load shaving strategies," Renewable and Sustainable Energy Reviews, 2017, early access.

[14] O. M. Toledo, D. O. Filho, and A. S. Diniz, "Distributed photovoltaic generation and energy storage systems: A review," Renewable and Sustainable Energy Reviews, vol. 14, no. 1, pp. 506-511, 2010.

[15] A. Chauhan and R. P. Saini, "A review on integrated renewable energy system based power generation for stand-alone applications: Configurations, storage options, sizing methodologies and control," Renewable and Sustainable Energy Reviews, vol. 38, no. 10, pp. 99120, 2014.

[16] T. Dragičević, X. Lu, J. C. Vasquez, and J. M. Guerrero, "DC microgrids - Part I: A review of control strategies and stabilization techniques," IEEE Transactions on Power Electronics, vol. 31, no. 7, pp. 4876-4891, 2016.

[17] H. Bevrani, A. Ghosh, and G. Ledwich, "Renewable energy sources and frequency regulation: survey and new perspectives," IET Renewable Power Generation, vol. 4, no. 5, pp. 438-457, 2010.

[18] S. Yan, S. C. Tan, C. K. Lee, B. Chaudhuri, and S. Y. R. Hui, "Use of smart loads for power quality improvement," IEEE Journal of Emerging and Selected Topics in Power Electronics, vol. 5, no. 1, pp. 504$512,2017$.

[19] I. Serban and C. Marinescu, "Battery energy storage system for frequency support in microgrids and with enhanced control features for uninterruptible supply of local loads," International Journal of Electrical Power \& Energy Systems, vol. 54, no. 1, pp. 432-441, 2014.

[20] M. Q. Wang and H. B. Gooi, "Spinning reserve estimation in microgrids," IEEE Transactions on Power Systems, vol. 26, no. 3, pp. 11641174, 2011.

[21] S. Succar and R. H. Williams, Compressed air energy storage: theory, resources, and applications for wind power, Princeton Environmental Institute, Energy Anal Group, 2008

[22] Y. Hida, R. Yokoyama, J. Shimizukawa, K. Iba, K. Tanaka, and T. Seki, "Load following operation of NAS battery by setting statistic margins to avoid risks," in IEEE PES General Meeting, Minneapolis, $M N, 2010$, pp. 1-5.

[23] R. Duan and J. Lee, "High-efficiency bidirectional DC-DC converter with coupled inductor," IET Power Electronics, vol. 5, no. 1, pp. 115123, 2012.

[24] F. Ibanez, J. M. Echeverria, J. Vadillo, and L. Fontan, "High-current rectifier topology applied to a 4-kW bidirectional DC-DC converter," IEEE Transactions on Industry Applications, vol. 50, no. 1, pp. 68-77, 2014.

[25] F. Krismer and J. W. Kolar, "Closed form solution for minimum conduction loss modulation of DAB converters," IEEE Transactions on Power Electronics, vol. 27, no. 1, pp. 174-188, 2012.

[26] B. Zhao, Q. Song, W. Liu, and Y. Sun, "Dead-time effect of the high-frequency isolated bidirectional full-bridge DC-DC converter: Comprehensive theoretical analysis and experimental verification," IEEE Transactions on Power Electronics, vol. 29, no. 4, pp. 16671680, 2014.

[27] J. H. Jung, H. S. Kim, M. H. Ryu, and J. W. Baek, "Design methodology of bidirectional CLLC resonant converter for high-frequency isolation of DC distribution systems," IEEE Transactions on Power
Electronics, vol. 28, no. 4, pp. 1741-1755, 2013.

[28] J. Zhang, J. S. Lai, R. Y. Kim, and W. Yu, "High-power density design of a soft-switching high-power bidirectional dc-dc converter," IEEE Transactions on Power Electronics, vol. 22, no. 4, pp. 1145-1153, 2007.

[29] S. Vazquez, S. M. Lukic, E. Galvan, L. G. Franquelo, and J. M. Carrasco, "Energy storage systems for transport and grid applications," IEEE Transactions on Industrial Electronics, vol. 57, no. 12, pp. 3881-3895, Dec. 2010.

[30] V. M. Pires, D. Foito, and J. F. Silva, "Fault tolerant multilevel topology based on three-phase H-bridge inverters for open-end winding induction motor drives," IEEE Transaction on Energy Conversion, vol. 32, no. 3, pp. 895-902, 2017.

[31] Z. Wang, Z. Zou, and Y. Zheng, "Design and control of a photovoltaic energy and SMES hybrid system with current-source grid inverter," IEEE Transaction on Application Superconductivity, vol. 23, no. 3, pp. 1051-1055, 2013.

[32] J. W. Kolar, T. Friedli, J. Rodriguez, and P. W. Wheeler, "Review of three-phase PWM AC-AC converter topologies," IEEE Transactions on Industrial Electronics, vol. 58, no. 11, pp. 4988-5006, Nov. 2011.

[33] M. Bragard, N. Soltau, S. Thomas, and R.W. De Doncker, "The balance of renewable sources and user demands in grids: Power electronics for modular battery energy storage systems," IEEE Transactions on Power Electronics, vol. 25, no. 12, pp. 3049-3056, 2010.

[34] M. Vasiladiotis and A. Rufer, "Analysis and control of modular multilevel converters with integrated battery energy storage," IEEE Transactions on Power Electronics, vol. 30, no. 1, pp. 163-175, 2015.

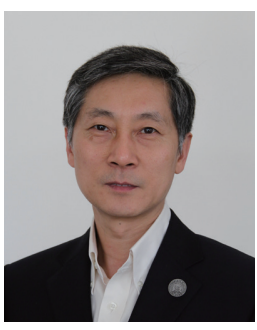

Liuchen Chang received the B.S.E.E. degree from the Northern Jiaotong University, Beijing, China, in 1982; the M.Sc. degree from the China Academy of Railway Sciences, Beijing, China, in 1984; and the Ph.D. degree from Queen's University, Kingston, ON, Canada, in 1991. He is currently a Professor at the University of New Brunswick, Fredericton, NB, Canada. He has published more than 340 journal and conference papers. His research interests and experience include distributed generation, renewable energy conversion, direct load controls in a smart grid environment, and power electronic converters. Dr. Chang is a fellow of Canadian Academy of Engineering.

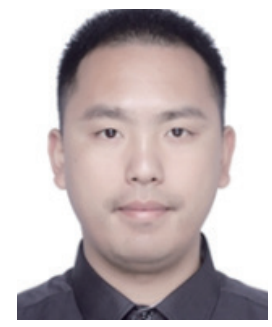

Wenping Zhang received the Ph.D. degree in electrical engineering from Zhejiang University, China, in 2016. He is currently a Post-Doc Fellowship at the University of New Brunswick, Fredericton, NB, Canada. From September 2012 to September 2013, he was a visiting scholar in electrical engineering at Texas A\&M University, College Station, TX, USA. His research interests include smart grid, energy storage, renewable generation, reliability of power electronics.

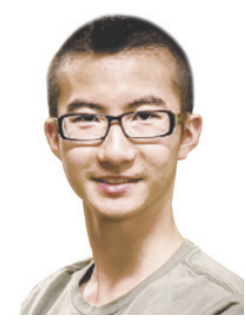

Shuang Xu received the B. Sc. E.E. in 2012 from Hefei University of Technology, Hefei, China. Currently he is pursuing the $\mathrm{Ph}$. $\mathrm{D}$. degree in electrical engineering at University of New Brunswick, Fredericton, Canada. His research interests include renewable energy systems, energy storage technologies, power electronics, power converters and micro-inverters. 


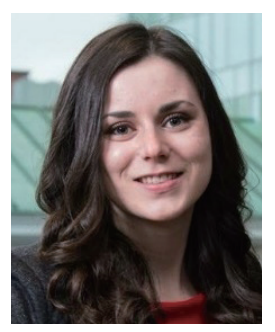

Katelin Spence received a B.Sc. EE. in 2016 from the University of New Brunswick, Fredericton,

Canada. She is now pursuing a M. Sc. degree in

Electrical Engineering, also at the University of

New Brunswick. Her research interest are renew-

able energy, power electronics, distributed genera-

tion, and energy storage. 